\title{
Overview of PCMs for concentrated solar power in the temperature range 200 to $350^{\circ} \mathrm{C}$
}

\author{
Thomas Bauer ${ }^{1, a}$, Doerte Laing ${ }^{1, b}$ and Rainer Tamme ${ }^{1, c}$ \\ ${ }^{1}$ Institute of Technical Thermodynamics, German Aerospace Center (DLR), \\ Pfaffenwaldring 38-40, 70569 Stuttgart, Germany \\ aThomas.Bauer@dlr.de, ${ }^{b}$ Doerte.Laing@dlr.de, ${ }^{\mathrm{C}}$ Rainer.Tamme@dlr.de
}

Keywords: Phase change material, Sodium Nitrate, Potassium Nitrate, Solar Thermal.

\begin{abstract}
Thermal energy storage is an essential advantage of solar thermal power plants. The present paper focuses on latent heat storage using a phase change material (PCM). The paper lists literature and gives the current status of PCM work in the temperature range 200 to $350{ }^{\circ} \mathrm{C}$. The system $\mathrm{KNO}_{3}-\mathrm{NaNO}_{3}$ is discussed in detail in terms of their thermo-physical properties in the liquid and solid phase. A comparison of literature data and own measurements for the density, heat capacity, thermal diffusivity and thermal conductivity is presented. Measurement results with the following methods are discussed: helium pycnometer, differential scanning calorimeter (DSC) and laser flash. Missing data of the thermal diffusivity and thermal conductivity are partly supplemented. Consistent thermo-physical properties in the liquid phase are presented.
\end{abstract}

\section{Introduction}

For concentrated solar thermal systems, the type of heat carrier fluid has a direct impact on the thermal energy storage design. The present paper focuses on pressurized water/steam as a carrier for collector technologies such as parabolic through, power tower or Fresnel. The pressure dependent condensation/evaporation of water/steam occurs between $200{ }^{\circ} \mathrm{C}\left(16\right.$ bar) and $350^{\circ} \mathrm{C}$ (165 bar). The high enthalpy condensation/evaporation process is almost isothermal and requires a suitable storage concept. Here, latent heat storage using a phase change material (PCM) is in particular advantageous. In this concept both the carrier and the storage material undergo a phase change. It is important to note that depending on the temperature level a suitable PCM has to be selected. Our ongoing PCM system research focuses on the sandwich concept using heat transfer enhancement fins made either from graphite or aluminum for latent heat storage systems [1]. For the system development and modeling, the solid-liquid phase change need to be understood. Essential properties are a suitable phase change temperature, a high melting enthalpy and the consideration of the volume change on melting. Other important criteria include thermal stability, handling, economics and the compatibility of the PCM with structural materials and heat transfer enhancement structures. In addition, knowledge of the PCM properties in the solid and liquid phase is important. Density variations can be important for a suitable thermo-mechanical design. The heat capacity determines the amount of additional heat being stored below and above the phase change temperature. The thermal diffusivity and conductivity have an impact on the storage power.

We discussed in a previous paper sodium nitrate $\left(\mathrm{NaNO}_{3}\right)$ with a melting temperature of $306{ }^{\circ} \mathrm{C}$ in terms of thermo-physical, nitrite formation and the compatibility with graphite [2]. This paper presents detailed material investigations of thermo-physical properties of a mixture of potassium nitrate $\left(\mathrm{KNO}_{3}\right)$ and $\mathrm{NaNO}_{3}$ with a minimum melting temperature of $222{ }^{\circ} \mathrm{C}$.

\section{Literature review of research on $\mathrm{PCMs}$ in the range $200-350{ }^{\circ} \mathrm{C}$}

Organic PCMs in the temperature range $120-250{ }^{\circ} \mathrm{C}$ have been discussed in a previous paper [3]. Typical challenges include thermal decomposition, high vapor pressure and reactions with oxygen. For these reasons organic PCMs are usually not considered in the higher temperature range. The number of available metals (or mixtures e.g. $\mathrm{Mg}-\mathrm{Zn}$ ) is limited in the temperature range $200-350{ }^{\circ} \mathrm{C}$ 
and disadvantages include toxicity (e.g. lead), economics (e.g. tin) and low latent heat (e.g. tin and lead). There are a few known solid-solid transitions of anhydrous salts. Examples are potassium and sodium hydroxide, as well as sodium sulfate. The latter has been studied for sensible heat storage where heat stored in the solid-solid transition could be used additionally [4].

In contrast, a large number of inorganic salt mixtures and several single salts with a melting temperature in the range 200 to $350{ }^{\circ} \mathrm{C}$ are known. This fact is due to the large number of salts with different cations and anions, as well as the good miscibility of many salts. For the considered temperature range, salts of interest mostly include alkali cations and anions such as nitrates, nitrites, hydroxides and chlorides. Lists of many potential salts and salt mixtures have been presented by different authors [5,6]. Table 1 shows only a limited number of PCMs that have been assessed in more detail in terms of their properties for thermal storage applications.

Table 1: PCMs in the temperature range $200-350{ }^{\circ} \mathrm{C}$ with work reported on material examinations.

\begin{tabular}{|l|c|c|c|c|}
\hline & $\mathbf{T}_{\mathbf{m}}\left[{ }^{\circ} \mathbf{C}\right]$ & $\mathbf{H ~}[\mathbf{J} / \mathbf{g}]$ & Major Research Focus & Literature \\
\hline $\mathrm{LiOH}(20 \mathrm{wt} \%)-\mathrm{NaOH}(80 \mathrm{wt} \%)$ & 215 & 280 & DSC examination & {$[7]$} \\
\hline $\mathrm{LiNO}_{3}$ & 252 & $380-530$ & Thermo-physical properties & {$[8]$} \\
\hline $\mathrm{KNO}_{3}(54 \mathrm{wt} \%)-\mathrm{NaNO}_{3}(46 \mathrm{wt} \%)$ & 222 & 100 & $\sim 1$ kg PCM Lab test & {$[9]$} \\
\hline $\mathrm{Ca}\left(\mathrm{NO}_{3}\right)_{2}(45 \mathrm{wt} \%)-\mathrm{NaNO}_{3}(55 \mathrm{wt} \%)$ & 230 & $\sim 110$ & $\sim 1$ kg PCM Lab test & {$[9]$} \\
\hline $\mathrm{KCl}-Z n C l_{2}^{\#}$ & $230-430$ & $200-220$ & Corrosion tests & {$[10]$} \\
\hline $\mathrm{NaNO}_{2}-\mathrm{NaOH}^{\#}$ & $232-265$ & $250-300$ & DSC examination & {$[11]$} \\
\hline $\mathrm{LiCl}^{\#-\mathrm{LiOH}^{\#}}$ & 262 & 485 & Thermo-physical properties & {$[8]$} \\
\hline $\mathrm{NaOH}^{-N_{a N O}}{ }^{\#}$ & $247-292$ & $240-300$ & 1.5 Ton PCM test module & {$[11-13]$} \\
\hline $\mathrm{NaNO}_{3}$ & 306 & 178 & DSC, Feasibility study & {$[14,15]$} \\
\hline $\mathrm{KNO}_{3}(94 \mathrm{wt} \%)-\mathrm{KCl}(6 \mathrm{wt} \%)$ & $\sim 320$ & $\sim 80$ & Feasibility study & {$[15]$} \\
\hline $\mathrm{KNO}_{3}$ & 334 & 98 & DSC, Feasibility study & {$[14,16,17]$} \\
\hline
\end{tabular}

\section{Experimental methods}

Measurements of alkali metal nitrates at higher temperatures are difficult for two reasons. First, in the liquid phase these nitrates strongly wet common container materials. Hence, a thin film of molten salt forms on the surface and spreads spontaneously. As a result, the salt can creep out of the container $[17,18]$. Second, there is nitrite formation in the melt in air and inert atmosphere. Hence, measurements refer to nitrite-nitrate systems instead of pure nitrates at higher temperatures [2]. For PCM utilization, molten salt properties just above the melting temperature are typically relevant.

Density. For the measurements at room temperature, $\mathrm{NaNO}_{3}$ and $\mathrm{KNO}_{3}$ salts had a purity of $>99,0 \%$. The following preparation method of the $\mathrm{KNO}_{3}-\mathrm{NaNO}_{3}(\mathrm{eu})$ and $\mathrm{NaNO}_{3}$ was used. Salt melting was performed $50 \mathrm{~K}$ above the melting temperature in glazed ceramic crucibles at atmospheric pressure in air. Afterwards, the salts were pulverized using a baffle mill. Salt pellets with a diameter of $40 \mathrm{~mm}$ and a weight of about $70 \mathrm{~g}$ were prepared by uniaxial compression with $50 \mathrm{~N} / \mathrm{mm}^{2}$. The utilization of compressed samples simplifies the handling. Also, a better utilization of the pycnometer volume is obtained (higher precision). The salt samples were dried for at least 24 hours at $110{ }^{\circ} \mathrm{C}$ and cooled in a desiccator with silica gel to exclude effects from moisture. The sample mass was recorded before and after the volume measurement. A commercial helium pycnometer (AccuPyc 1330, Micromeritics) was used to determine the sample volume. The volume measurements were repeated five times with the same sample at $24{ }^{\circ} \mathrm{C}$ and the volume value varied less than $+/-0.01 \%$ from the average. The described procedure (melting, drying, compression, density determination) was repeated three times for both salts.

Heat capacity. Heat capacity measurements were made with a heat flux type DSC (Netzsch DSC404) in Argon flow $(100 \mathrm{ml} / \mathrm{min})$ with a heating rate of $10 \mathrm{~K} / \mathrm{min} . \mathrm{NaNO}_{3}$ and $\mathrm{KNO}_{3}$ were purchased from Merck (purity $>99,99 \%$ ). The salts were pre-melted, quenched, ground and dried at least 24 hours at $110^{\circ} \mathrm{C}$ before the measurement. The sample mass of about $20 \mathrm{mg}$ was checked before and after the DSC measurement with a microbalance. Aluminum crucibles with a lid were used. Sapphire was utilized as heat capacity reference material with data recommended by Netzsch. 
Thermal diffusivity. These measurements in the liquid and partly in the solid phase were carried out by the laser flash method using a three layer arrangement with a crucible and a commercial apparatus (Netzsch LFA457). Aluminum crucibles with a lid were used. A single laser pulse beam illuminates the bottom area of the crucible. The heat penetrates through three layers: the crucible (thickness $0.26 \mathrm{~mm}$ ), an either liquid or solid salt sample $(0.52 \mathrm{~mm}$, diameter $12 \mathrm{~mm})$ and the lid $(0.29 \mathrm{~mm})$. The bottom and top of this crucible were coated with a thin graphite layer in order to enhance the absorption and emission. The temperature rise versus time at the rear surface of the lid is measured by a liquid nitrogen cooled InSb photocell. The atmosphere was nitrogen $(100 \mathrm{ml} / \mathrm{min})$. A mathematical model describes the temperature rise versus time signal and was fitted to the experimental data using a non-linear regression algorithm. This three layer model includes the thicknesses of the three layers and thermo-physical properties of the layers, as well as corrections of heat losses and laser pulse lengths. The salt quality and preparation was identical to the DSC measurements. First, the compressed salt powder was melted in the crucible. Subsequently, the thermal diffusivities in the liquid and then in the solid state were measured isothermally. At least three measurement series with a newly prepared crucible fill and at least three shots per temperature were carried out. The salt layer thickness is the major cause of measurement uncertainty. For example an error of $0.01 \mathrm{~mm}$ in thickness leads to an error of $3 \%$ in the diffusivity value. Another aspect is the wetting of the aluminum crucible by the molten salt and the distribution of the molten salt in the crucible. An accurate measurement can be checked by the distribution of the solid salt after the measurement, as well as the analysis of the measurement signal versus time. The accuracy of method was verified by pure water measurements at room temperature and comparison with literature values [19], as well as reference measurements of molten $\mathrm{NaNO}_{3}[2]$.

\section{Properties of $\mathrm{KNO}_{3}-\mathrm{NaNO}_{3}$ as a $\mathrm{PCM}$ (Literature and Experiments)}

The binary system $\mathrm{KNO}_{3}-\mathrm{NaNO}_{3}$ is well known and molten salt mixtures are commercially important for applications such as heat-treatment baths, as heat transfer fluids and as sensible heat storage media (molten salt tanks)[20]. The system has been studied in more than 40 papers since 1857. Overview papers have been written by Rogers and Janz [21], Berg and Kerridge [22] and Zhang et al. [23], as well as others cited in these references. Details of the phase diagram are not yet fully agreed. A discussion whether this system is of continuous solid solution or eutectic type can be found elsewhere [22,23]. Fig. 1 summarizes some phase diagrams of the $\mathrm{KNO}_{3}-\mathrm{NaNO}_{3}$ system. This figure shows the discrepancies of the solidus und liquidus among the authors [23]. At least in recent literature, it is generally agreed that the composition with a minimum melting temperature is $\mathrm{KNO}_{3}(50 \mathrm{~mol} \%)-\mathrm{NaNO}_{3}(50 \mathrm{~mol} \%)$ [21-23], or alternatively in terms of masses about $\mathrm{KNO}_{3}(54 \mathrm{wt} \%)-\mathrm{NaNO}_{3}(46 \mathrm{wt} \%)$. For simplicity, the following text uses the abbreviation $\mathrm{KNO}_{3}$ $\mathrm{NaNO}_{3}(\mathrm{eu})$ for this composition.

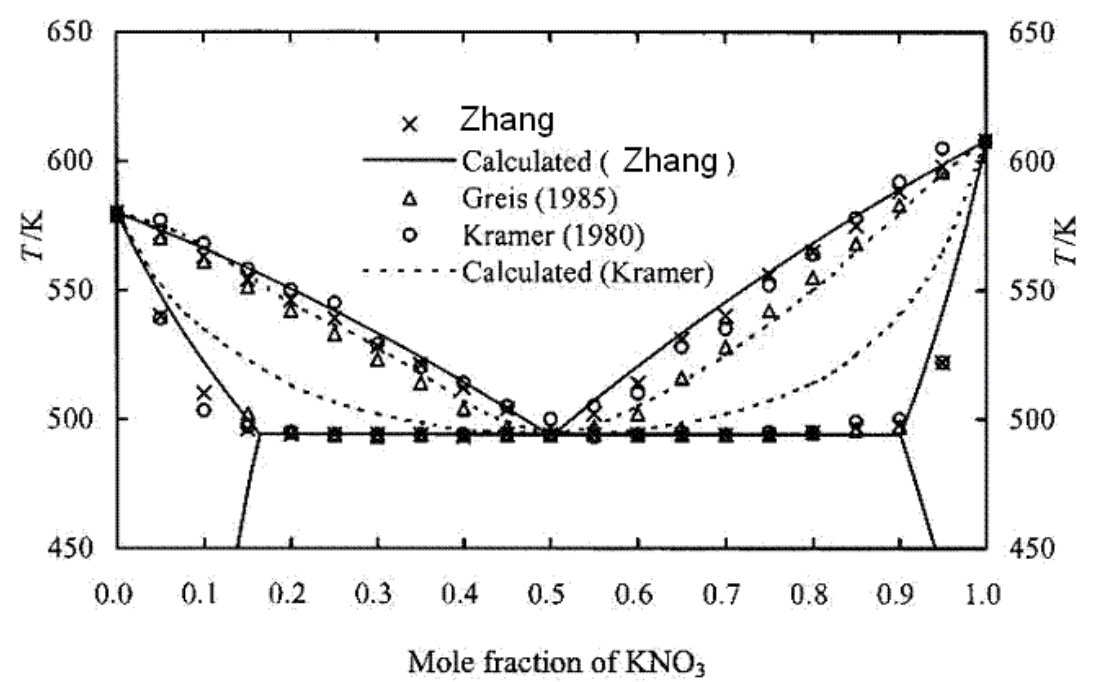

Fig. 1: Overview of different phase diagrams of the system $\mathrm{KNO}_{3}-\mathrm{NaNO}_{3}$ [23]. 
Phase change. A solid-solid transition of the $\mathrm{KNO}_{3}-\mathrm{NaNO}_{3}(\mathrm{eu})$ system is reported at $113{ }^{\circ} \mathrm{C}$ (two times) and $115{ }^{\circ} \mathrm{C}[21,22]$. Kamimoto reports a value of $114{ }^{\circ} \mathrm{C}$ for annealed samples and 106 ${ }^{\circ} \mathrm{C}$ for quenched and ground samples [24]. For this transition, enthalpy values of 34 and $38 \mathrm{~J} / \mathrm{g}$ have been reported [21]. Zhang discussed the minimum melting temperatures. Nine measured values in a range from 220 to $227^{\circ} \mathrm{C}$ are reported [23]. The average of this nine values results in a melting temperature of $222{ }^{\circ} \mathrm{C}$. Also, four of the nine reported values are $222{ }^{\circ} \mathrm{C}$. Reported experimental melting enthalpies include 114, 112, 110, 101 and $102 \mathrm{~J} / \mathrm{g}$ [21,24,25]. Higher values are from older drop calorimeter measurements. Newer values are measured by the DSC method and tend to be lower. The average of these values is $108 \mathrm{~J} / \mathrm{g}$. The DSC experimental value of $144 \mathrm{~J} / \mathrm{g}$ by Marchidan seems to be exceptionally high and is not included here.

Density. It appears that there are no density values for $\mathrm{KNO}_{3}-\mathrm{NaNO}_{3}(\mathrm{eu})$ at room temperature available. For this reason, own density measurements at room temperature of $\mathrm{KNO}_{3}-\mathrm{NaNO}_{3}(\mathrm{eu})$ and $\mathrm{NaNO}_{3}$ were carried out. Measurements of $\mathrm{NaNO}_{3}$ served as a reference to confirm the applied method. The three measured density values were: $2.2571,2.2569$ and $2.2566 \mathrm{~g} / \mathrm{cm}^{3}$. It can be seen that the reproducibility of the measurement is high. A good agreement of the density value of $\mathrm{NaNO}_{3}$ from this experiment and the literature was obtained $\left(2.261 \mathrm{~g} / \mathrm{cm}^{3}\right.$ at $\left.25^{\circ} \mathrm{C}\right)[26]$. The measured room temperature value of $\mathrm{KNO}_{3}-\mathrm{NaNO}_{3}(\mathrm{eu})$ were $2.1786,2.1774$ and $2.1769 \mathrm{~g} / \mathrm{cm}^{3}$. Fig. 2 shows the average of these three values compared to a value obtained by simple addition of the single $\mathrm{KNO}_{3}$ and $\mathrm{NaNO}_{3}$ volumes with density values of the single salts at $25{ }^{\circ} \mathrm{C}$ taken from literature [26]. It can be seen that the calculated and measured values agree closely. Literature data of the linear expansion coefficient of $\mathrm{KNO}_{3}-\mathrm{NaNO}_{3}(\mathrm{eu})$ in the solid state could not be identified. The densities just below and above the melting temperature have been reported by Schinke [27]. For simplicity, a straight line between data by Schinke and our measurements is defined (Fig. 2). It can be expected, that the solid-solid transition causes some deviation from this ideal line. Molten salt density measurements are available from several authors [25,28-31]. These values have been averaged and extrapolated to the melting temperature. Extrapolated molten salt data agree with measured values from Schinke.

Heat capacity. Data are available from several authors (Fig. 2)[21,24,25,32,33]. The scattering of the $\mathrm{KNO}_{3}-\mathrm{NaNO}_{3}$ data in the solid phase is much stronger compared to $\mathrm{NaNO}_{3}$ [2]. This is also due to the fact that some authors give constant values for a limited temperature range.

Own measurements show at around $100{ }^{\circ} \mathrm{C}$ a peak that can be attributed to the solid-solid transition. Our capacity values tend to be slightly lower compared to those of other authors. Liquid phase values agree closely among the authors, except older values from Voskresenskaya which are excluded here. Also, drop calorimeter data from Nguyen-Duy match closely (in contrast to $\mathrm{NaNO}_{3}$ data [2]). As for $\mathrm{NaNO}_{3}$, a constant heat capacity of molten $\mathrm{KNO}_{3}-\mathrm{NaNO}_{3}$ mixtures can be assumed [21]. We computed an average value from four literature sources and our own measurement. All measurements have a deviation of less than $+/-4 \%$ of this average value.

Thermal diffusivity. Literature data could not be identified. Own $\mathrm{KNO}_{3}-\mathrm{NaNO}_{3}(\mathrm{eu})$ measurements showed that the reproducibility in the liquid phase is lower compared to $\mathrm{NaNO}_{3}$ [2]. The three measurement series had a deviation of less than $+/-9 \%$ from the average value of these measurements. This can be attributed to the less ideal salt distribution for $\mathrm{KNO}_{3}-\mathrm{NaNO}_{3}(\mathrm{eu})$ in the crucible compared to $\mathrm{NaNO}_{3}$. The average value agrees with a calculated value using the relation a $=\mathrm{k} /\left(\rho \cdot \mathrm{c}_{\mathrm{p}}\right)$ and averaged data presented in the boxes in Fig. 2 . The measurements can also give some indication of the diffusivity in the solid phase. The diffusivity was very similar in the solid and liquid phase and almost constant in the solid phase. These characteristics are fundamentally different from those of $\mathrm{NaNO}_{3}$ with a diffusivity drop from room to the melting temperature [2].

Thermal conductivity. No literature data of solid $\mathrm{KNO}_{3}-\mathrm{NaNO}_{3}(\mathrm{eu})$ could be identified. Several experimental values of molten mixture are reported (Fig. 2)[34-39]. Values from Omotani, Tufeu and DiGuilio showed a closer agreement. These values were averaged to calculate the diffusivity. 

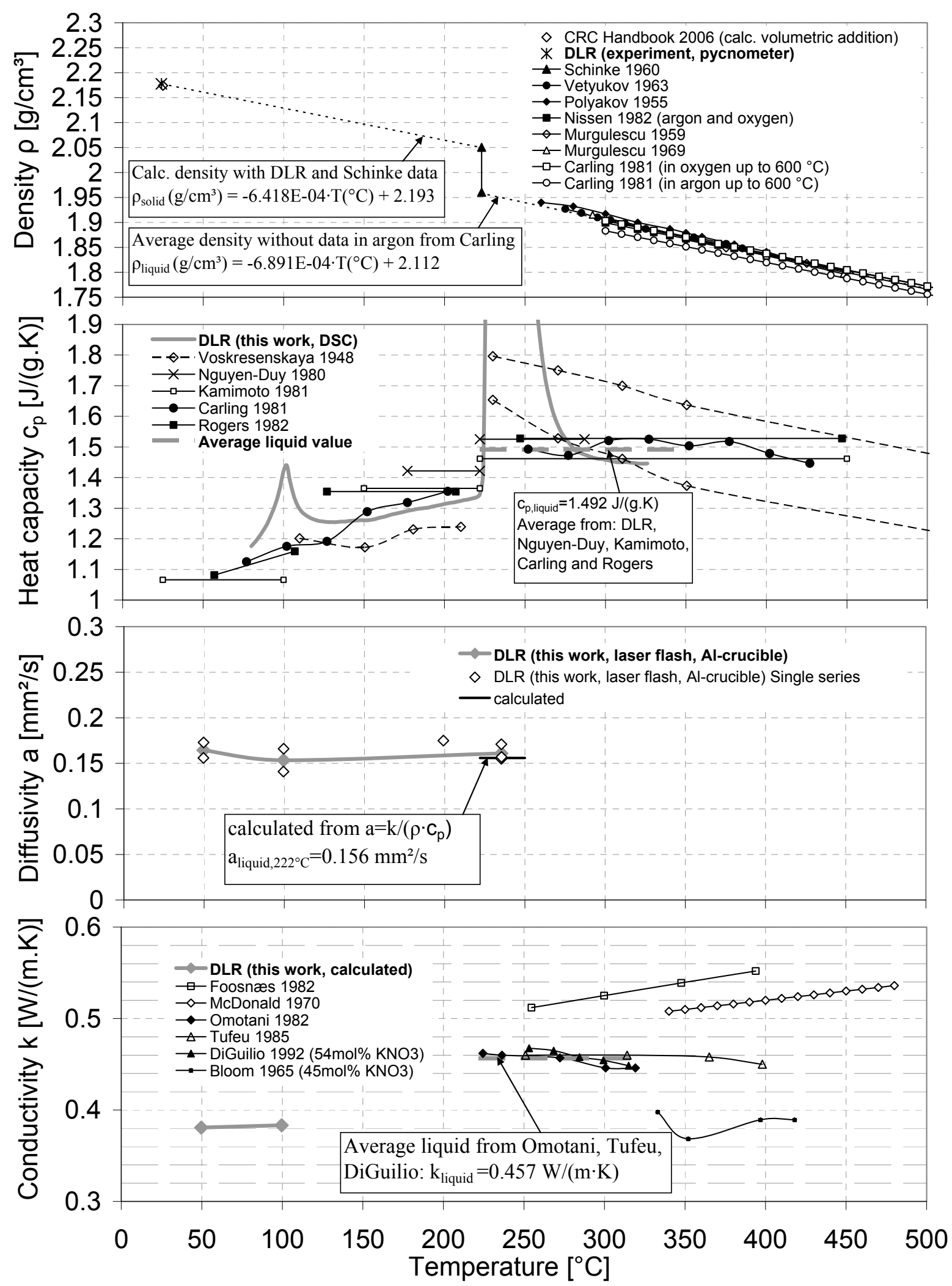

Fig. 2: Thermo-physical properties of $\mathrm{KNO}_{3}-\mathrm{NaNO}_{3}(\mathrm{eu})$; the melting temperature is $222{ }^{\circ} \mathrm{C}$.

\section{Summary}

This paper gave an overview of phase change materials (PCMs) in the temperature range 200 to $350{ }^{\circ} \mathrm{C}$ for solar thermal power generation. A table with the development status of eleven PCMs in this range was presented. We assessed two of these PCMs in depth. Results of NaNO3 were reported in a previous paper [2]. The presented paper focused on the phase change properties and the thermo-physical properties of the minimum melting system $\mathrm{KNO}_{3}(54 \mathrm{wt} \%)-\mathrm{NaNO}_{3}(46 \mathrm{wt} \%)$. For 
the melting temperature and enthalpy, average literature values of $222{ }^{\circ} \mathrm{C}$ and $108 \mathrm{~J} / \mathrm{g}$ were identified. We presented own experimental results and a comprehensive literature review of the following thermo-physical properties: density $\rho$, heat capacity $c_{p}$, thermal diffusivity a and thermal conductivity $\mathrm{k}$. The work identified consistent thermo-physical molten salt data according to the relation $\mathrm{k}=\mathrm{a} \cdot \rho \cdot \mathrm{c}_{\mathrm{p}}$ close to the melting temperature with values of $\rho=1.959 \mathrm{~g} / \mathrm{cm}^{3}, \mathrm{c}_{\mathrm{p}}=1.492 \mathrm{~J} / \mathrm{gK}$, $\mathrm{a}=0.1564 \mathrm{~mm}^{2} / \mathrm{s}$ and $\mathrm{k}=0.457 \mathrm{~W} / \mathrm{mK}$. Solid phase heat capacity data are available and they could be confirmed by own DSC-measurements. No other thermo-physical solid phase data could be identified in literature and measurement results of these unknown properties were presented. Laserflash measurements of the solid-phase diffusivity showed an almost constant value that was similar to the molten salt. In general, more research is required in order to establish a better understanding of the heat transport properties in the solid phase (e.g. impact of crystal structure). Density data at room temperature were obtained by Pycnometer measurements. These measurements agree closely with calculated values using the volume fraction and density of the single salts.

The authors acknowledge funding by the German Federal Ministry for the Environment, Nature Conservation and Nuclear Safety (ITES project, Contract No. 03UM0064).

\section{References}

[1] W.-D. Steinmann, D. Laing, R. Tamme: J. Sol. Energy Eng. Vol. 131 (2009), p. 041009/1-4.

[2] T. Bauer et al.: Elec. Proc. 11th Int. Conf. on Therm. Energy Storage-Effstock (2009), Paper 4.

[3] T. Bauer et al.: Elec. Proc. of the Eurosun Conf., Lisbon (2008), Paper 163.

[4] A. Verma, K.E. Johnson, E.O. Sherman: Can. J. of Chem. Eng. Vol. 54 (1976), p. 285-289.

[5] G.J. Janz, C.B. Allen, J.R. Downey, R.P.T. Tomkins: NSRDS-NBS 61 Part I.

[6] M.M. Kenisarin: Renewable and Sustainable Energy Reviews Vol. 14 (2010), p. 955-970.

[7] Y. Takahashi et al.: Thermochimica Acta Vol. 121 (1987), p. 193-202.

[8] R.P.Tye, J.G. Bourne, A.O. Desjarlais: Thermal Energy Storage Material Thermophysical Property Measurement and Heat Transfer Impact, NASA Report, NAS-3-19716 (1976).

[9] M. Kamimoto, T. Tanaka, T. Tani, T. Horigome: Solar Energy Vol. 24 (1980), p. 581-587.

[10] D. Heine, F. Heess, M. Groll: Proc. 14th lntersoc. Energy Conv. Eng. Conf. (1979), p. 459-466.

[11] Y. Takahashi et al.: Thermochimica Acta Vol. 123 (1988), p. 233-245.

[12] B.M. Cohen et al.: Development of a phase-change thermal storage system using modified anhydrous sodium hydroxide for solar electric power generation, Report, Comstock \& Wescott DOE/NASA/061579/1 (1978).

[13] R.J. Calkins et al.: Conceptual design selection and development of a latent-heat thermal-energy-storage subsystem for a saturated-steam solar receiver and load, Sandia Lab. Rep. SAND-81-8184 (1981).

[14] Y. Takahashi, R. Sakamoto, M. Kamimoto: Int. J. of Thermoph. Vol. 9 (1988), p. 1081-1090.

[15] H. Michels, R. Pitz-Paal: Solar Energy Vol. 81 (2007), p. 829-837.

[16] R.W. Carling: Thermochimica Acta Vol. 60 (1983), p. 265-275.

[17] D.A. Nissen, D.E. Meeker: Inorganic Chemistry Vol. 22 (1983), p. 716-721.

[18] C.M. Kramer, Z.A. Munir, J.V. Volponi: Thermochimica Acta Vol. 55 (1982), p. 11-17.

[19] Y.S. Touloukian et al.: Thermophysical Properties of Matter, Vol. 10 (1979) Plenum.

[20] W. Laue et al.: Nitrates and Nitrites, in Ullmann's Encycl. of Industrial Chemistry (1998) 6. Edition.

[21] D.J. Rogers, G.J. Janz: Journal of Chemical \& Engineering Data Vol. 27 (1982), p. 424-428.

[22] R.W. Berg, D.H. Kerridge: Dalton Transactions (2004), p. 2224-2229.

[23] X. Zhang, J. Tian, K. Xu, Y. Gao: J. of Phase Equil. and Diffusion Vol. 24 (2003), p. 441-446.

[24] M. Kamimoto: Thermochimica Acta Vol. 49 (1981), p. 319-331.

[25] R.W. Carling et al.: Molten nitrate salt technology development, Sandia Laboratory Report, SAND80$8052(1981)$.

[26] D.R. Lide: Physical Constants of Inorganic Compounds, in CRC Handbook of Chemistry and Physics, Taylor \& Francis (2006-2007) 87. Edition.

[27] H. Schinke, F. Sauerwald: Z. für anorganische Chemie Vol. 304 (1960) p. 25-36 (in German).

[28] M.M. Vetyukov et al.: Zhurnal Prikladnoi Khimii Vol. 36 (1963) p. 2385-2391.

[29] V.D. Polyakov et al.: Izvest. Siktora Fiz. Khim. Anal. Vol. 26 (1955), p. 164-172 (in Russian)

[30] D.A. Nissen: Journal of Chemical \& Engineering Data Vol. 27, (1982) p. 269-273.

[31] I.G. Murgulescu, Ş Zuca: Electrochimica Acta Vol. 14 (1969), p. 519-526.

[32] P. Nguyen-Duy, E.A. Dancy: Thermochimica Acta Vol. 39 (1980), p. 95-102.

[33] N.K. Voskresenskaya et al.: Zhurnal Neorg. Khimii Vol. 21 (1948), p. 18-25 (in Russian).

[34] R. Tufeu, J.P. Petitet, L. Denielou, B. Le Neindre: Int. J. of Therm. Vol. 6 (1985), p. 315-330.

[35] T. Foosnæs et al.: Thermal Conductivity of Nitrate Mixtures, Sandia Lab. Report SAND80-8191 (1982).

[36] J. McDonald, H.D. Davis: Journal of Physical Chemistry Vol. 74 (1970), p. 725-730.

[37] T. Omotani, A. Nagashima: J. Chem. Eng. Data Vol. 29 (1984), p. 1-3.

[38] R.M. DiGuilio, A.S. Teja: International Journal of Thermophysics Vol. 13 (1992), p. 575-592.

[39] H. Bloom, A. Doroszkowski, S.B. Tricklebank: Aus. J. of Chem. Vol. 18 (1965), p. 1171-1176. 